IMECE2010-40926

\title{
HEAT-PIPE ASSISTED THERMOELECTRIC GENERATORS FOR EXHAUST GAS APPLICATIONS
}

\author{
L.M. Goncalves \\ Dpt. Industrial Electronics \\ University of Minho \\ 4500-058 Guimaraes - Portugal \\ Joaquim Antunes \\ Dpt. Industrial Electronics \\ University of Minho \\ 4500-058 Guimaraes - Portugal
}

\author{
Jorge Martins \\ Dpt. Mech. Engineering \\ University of Minho \\ 4800-058 Guimaraes - Portugal \\ Romeu Rocha \\ Dpt. Industrial Electronics \\ University of Minho \\ 4800-058 Guimaraes - Portugal
}

\author{
Francisco P. Brito \\ Dpt. Mech. Engineering \\ University of Minho \\ 4800-058 Guimaraes Portugal
}

\section{ABSTRACT}

Millions of hybrid cars are already running on our roads with the purpose of reducing fossil fuel dependence. One of their main advantages is the recovery of wasted energy, namely by brake recovery. However, there are other sources of wasted energy in a car powered by an internal combustion engine, such as the heat lost through the cooling system, lubrication system (oil coolers) and in the exhaust system. These energies can be recuperated by the use of thermoelectric generators (TEG) based on the Seebeck effect, which transform heat directly into electricity

To recover the energy from the hot (up to more than 700 ${ }^{\circ} \mathrm{C}$ ) exhaust gases it is possible to use controlled heat transfer, but this would limit the heat transfer potential at partial loads, as commercialy available TEG are limited by their maximum allowable temperature $\left(\sim 250^{\circ} \mathrm{C}\right)$. Therefore Heat Pipes were used as an alternative heat transfer mean, so it would be possible to retain the heat transfer potential, while controlling the maximum temperature at a reasonable level. This is the method to recover the exhaust heat presented in this work.

Numerical simulations were performed to assess the potential for this design, involving internal combustion engine simulation, thermoelectric generators simulation and heat transfer modelling. Additionally, the use of variable conductance heat pipes (VCHP) is discussed, as a means of achieving TEG module maximum temperature limitation.

\section{NOMENCLATURE}

A inner area of the pipe

$c_{p} \quad$ Specific heat (constant pressure)

$D \quad$ heat pipe diameter

FEM Finite element modelling

HP Heat pipes

$h \quad$ heat transfer coefficient gases/pipe $\quad\left[\mathrm{Wm}^{-2} \mathrm{~K}^{-1}\right]$

I Electrical intensity

$K_{P} \quad$ Thermal conductance of the TEG

$k \quad$ Thermal conductivity of the TEG

M Torque

Mass flow rate

$\begin{array}{ll}N & \text { Rotational speed } \\ N u_{D} & \text { Nusselt Number }\end{array}$

$\begin{array}{ll}\mathrm{Nu}_{\mathrm{D}} & \text { Nusselt } \\ n & \text { number of modules }\end{array}$

$\left[\mathrm{m}^{2}\right]$
$\left[\mathrm{Wkg}^{-1} \mathrm{~K}^{-1}\right]$

$[\mathrm{m}]$

$P_{o} \quad$ output electrical power

$\operatorname{Pr} \quad$ Pandtl number

$\dot{Q}_{c} \quad$ heat transfer rate from the exhaust to the block

\section{[A]}

$\left[\mathrm{WK}^{-1}\right]$ $\left[\mathrm{Wm}^{-1} \mathrm{~K}^{-1}\right]$

[Nm]

$\left[\mathrm{kgs}^{-1}\right]$

[rpm]

$[-]$

$[-]$

[W]

$[-]$ 


\begin{tabular}{|c|c|c|}
\hline$\dot{Q}_{i}$ & heat transfer rate inner gases/air & {$[\mathrm{W}]$} \\
\hline$R_{i}$ & Electrical resistance of the TEG & {$[\Omega]$} \\
\hline$R_{L}$ & Load resistance & {$[\Omega]$} \\
\hline$S$ & Mean Seebeck coefficient & {$\left[\mathrm{VK}^{-1}\right]$} \\
\hline TEG & Thermoelectric Generator & \\
\hline$T$ & Temperature & {$[\mathrm{K}]$} \\
\hline$T_{a m b}$ & Ambient temperature & {$\left[{ }^{\circ} \mathrm{C}\right]$} \\
\hline$T_{C}$ & Temperature at the cold side of the TEG & {$[\mathrm{K}]$} \\
\hline$T_{H}$ & Temperature at the hot side of the TEG & {$[\mathrm{K}]$} \\
\hline$T_{i}$ & Exhaust gas initial temperature (entry) & {$\left[{ }^{\circ} \mathrm{C}\right]$} \\
\hline$T_{M}$ & Mean temperature of the TEG $\left(\mathrm{T}_{\mathrm{C}}+\mathrm{T}_{\mathrm{H}}\right) / 2$. & {$[\mathrm{K}]$} \\
\hline$T_{o}$ & Exhaust gas outlet temperature & {$\left[{ }^{\circ} \mathrm{C}\right]$} \\
\hline$V$ & Electric voltage difference & {$[\mathrm{V}]$} \\
\hline$V_{O}$ & Total voltage generated in TEG & {$[\mathrm{V}$} \\
\hline VCHP & Variable Conductance Heat Pipes & \\
\hline$v$ & gas velocity & {$\left[\mathrm{ms}^{-1}\right.$} \\
\hline WOT & Wide Open Throttle & \\
\hline$Z T$ & Figure-of-merit of the TEG & {$\left[\mathrm{W} \Omega^{-1}\right]$} \\
\hline$Z T_{M}$ & ZT of the device, at temperature $T_{M}$ & {$\left[\mathrm{~W} \Omega^{-1}\right]$} \\
\hline$\alpha$ & Seebeck coefficient & {$\left[\mathrm{VK}^{-1}\right]$} \\
\hline$\Delta$ & Difference & {$[-]$} \\
\hline$\eta$ & Conversion efficiency & \\
\hline$\mu$ & Gas dynamic viscosity & {$[$ Pa.s $]$} \\
\hline$\rho$ & mean electric resistivity & {$[\Omega r$} \\
\hline & gas density & [kg.m \\
\hline
\end{tabular}

\section{INTRODUCTION}

In the search for the ultimate efficiency during car operation, researchers and vehicle manufacturers have turned to the use of hybrid vehicles, where one of the main advantages is brake energy recovery [1]. Other manufacturers, without using the full potential (and cost) of the hybrid system, attempt to reduce engine power to produce in-board electricity, by generating all the electric power necessary for the auxiliaries of the car during deceleration and braking. In terms of exhaust gas enthalpy recovery, this can be achieved in part by the used of the so called over-expanded cycles [2]. However, even when using these high efficiency cycles, the exhaust gas temperature is still high, and therefore with potential for energy recovery.

There are some experimental attempts for exhaust heat recovery by the use of thermoelectric generators [3], but the potential for power recovery is just enough to meet the electric demands of the various electrical accessories. However, with a properly designed system, it should be possible to recover a significantly higher amount of energy [4], when adding the potential of the cooling system, lubrication system and exhaust system. When an internal combustion engine is running at part load, the energy released by the fuel in the combustion is converted into useful work, directed to the cooling system and released in the form of exhaust gas enthalpy in, more or less, equal parts $[5,6]$. Therefore, the power available at the exhaust and for cooling (including water and oil) is roughly twice the mechanical power used for traction (fig. 1). Even if a small percentage of this waste energy could be recovered, the gains in efficiency for the vehicle would be important.

The thermal energies from the cooling, lubricating and exhaust systems can be recovered by the use of thermoelectric generators (TEG) based on the Seebeck effect, which transform it directly into electricity. It is almost straightforward to recover the energy from the cooling $\left(100^{\circ} \mathrm{C}\right.$ max.) and lubrication (120 ${ }^{\circ} \mathrm{C}$ max.) systems even if this conversion has a very low efficiency.

Recent papers [7] refer an efficiency of heat recovery (to electricity) using advanced thermoelectric generators of $5 \%$, which would translate into an extra $6 \%$ (1\% from coolant, $5 \%$ from exhaust) of available (electric) energy in a hybrid car. Consequently, the engine with a 33\% efficiency could "find" extra mechanical power, leading to $38 \%$ efficiency, and a $5 \%$ in fuel savings.

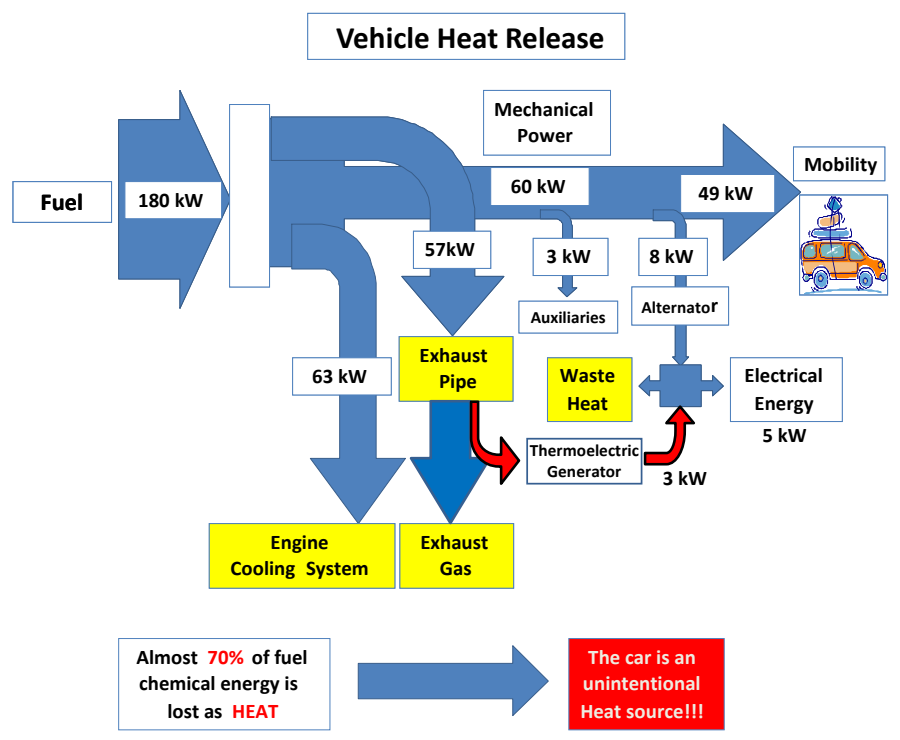

FIGURE 1 - Engine heat balance

The major potential, and the most problematic from the heat recovery perspective, is the energy recovery of the hot (up to more than $700{ }^{\circ} \mathrm{C}$ ) exhaust gases. There is still no efficient TEG that is able to tolerate this type of temperature, so, it is necessary to downgrade it. This could easily be done by placing controlled heat transfer materials between the gases and the modules, achieving the required temperature difference. But this is difficult to do in an efficient way, as the available power and temperature on the exhaust changes dramatically with the engine load and speed. Furthermore, the system should be designed for the maximum power (to avoid module meltdown), which would greatly reduce the power available for the TEG during part load operation, since the power generated in the TEG is proportional to the square of the temperature. The use of Heat Pipes enables the matching of the thermal load of TEGs 
to the available heat in the exhaust gases, thus improving efficiency in energy conversion at different engine loads and speeds.

\section{ENGINE AND EXHAUST GAS MODEL}

To evaluate the exhaust conditions (temperature and power) to be used as data input for the thermoelectric generator model, data from a running engine, previously tested by the research team [8] was used for this study.

The engine dimensions are as follows:

- $\quad$ Stroke $=55 \mathrm{~mm}$

- $\quad$ Diameter $=70 \mathrm{~mm}$

- $\quad$ Compression Ratio = 11:1

In order to achieve the required $60 \mathrm{~kW}$, we assumed a 6-cylinder engine, with the above dimensions, with a total capacity of $1270 \mathrm{~cm}^{3}$. The thermal power levels at the exhaust were calculated taking into account the enthalpy difference of the exhaust gas, from its temperature to ambient ( $\left.\dot{m} c_{p}\left(T_{i}-T_{a m b}\right)\right)$. However, the actual potential value for heat transfer power from the gases is somehow reduced, as they cannot be cooled below the heat pipe temperature $\left(\dot{m} c_{p}\left(T_{i}-T_{h}\right)\right.$ ), which results in a lower value. The experimental results, for exhaust gas temperature and mass flow, in terms of engine speed and torque, can be seen in fig. 2 .

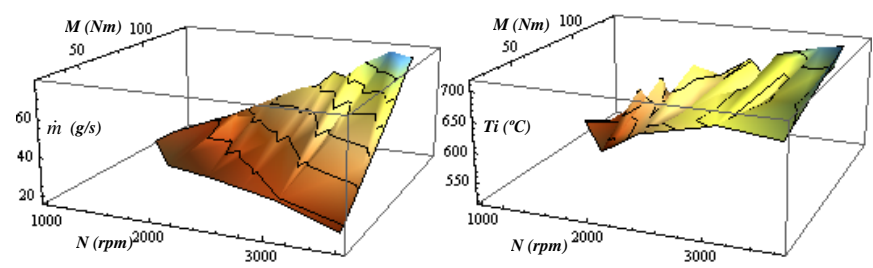

FIGURE 2 - Measured mass flow and temperature in the exhaust of an engine, as function of rotational speed (N) and torque (T)

Unfortunately, this engine was run only up to $3500 \mathrm{rpm}$, without showing the extreme values of exhaust gas temperature and mass flow for the full power conditions (6500 rpm).

With that limitation, we decided to use an internal combustion engine computer model, to get the data for the same engine at the maximum power condition. This computer program was developed by the Internal Combustion Engines team at the University of Minho [9], enabling to model a S.I. engine at different conditions of load and speed. The program, written in MATLAB/SIMULINK, has been used to simulate engine behaviour, namely the comparison between the engine working under the Otto cycle and under the Miller cycle [8].

In order to establish the exhaust gas properties (temperature and mass flow) this model was run at various conditions (fig. 3):

- medium load (intake manifold at 0.65 bar), 4000, 4500 and $5000 \mathrm{rpm}$

- WOT (intake manifold at 1.0 bar), 4000, 4500, 5000, 5500, 6000 and $6500 \mathrm{rpm}$
This enabled the full engine mapping seen in fig. 3.
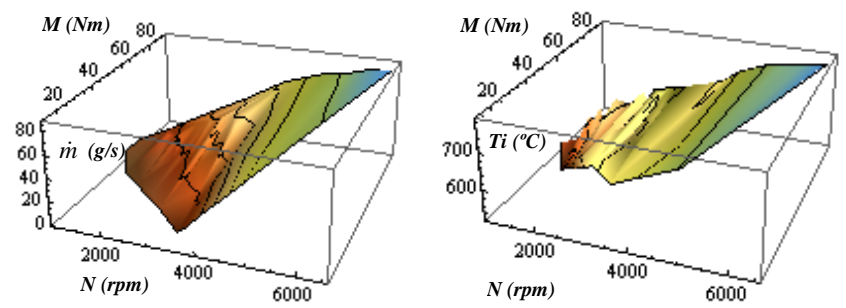

FIGURE 3 - Calculated and measured mass flow and temperature in the exhaust of a $60 \mathrm{~kW}$ engine. Six contour plots are also presented equally distributed from minimum to maximum of scales.

\section{THERMOELECTRIC GENERATORS}

A temperature difference can be converted to a voltage using the Seebeck effect of a thermoelectric module (fig. 4). In the Seebeck effect, a temperature difference between the junctions of two different materials produces an electric voltage and electric current flows when the electric circuit is closed. This effect is quantified by the Seebeck coefficient, $\alpha$, as represented in eq. 1 :

$$
\alpha=\frac{\Delta V}{\Delta T}
$$

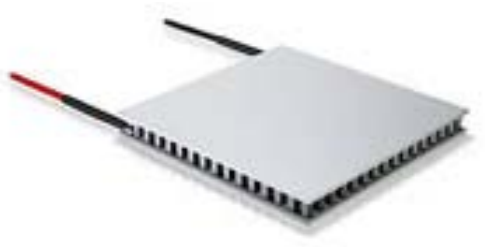

FIGURE 4 - Thermoelectric module.

A good thermoelectric generator device [10] should have a high Seebeck coefficient, and at the same time a low electrical resistance $-R_{i}$ (thus allowing higher currents) and a low thermal conductance $K_{P}$ (thus reducing heat loss through the generator). The figure-of-merit $(Z T)$ is used to quantify the performance of a thermoelectric module [11], or a single thermoelectric material, at a specific temperature T:

$$
Z T=\frac{\alpha^{2}}{R_{i} K_{P}} T=\frac{\alpha^{2}}{\rho k} T
$$

where $\alpha$ is the Seebeck coefficient, $\rho$ is the mean electric resistivity, $k$ is the mean thermal conductivity and $T$ the temperature $(\mathrm{K})$. High $Z T$ thermoelectric materials for high temperature are still under development [12]. The efficiency of a thermoelectric generator can be calculated with Eq. 3, 
considering the output electrical power $\left(P_{O}\right)$ and the input thermal power $\left(\dot{Q}_{c}\right)[13]$ :

$$
\eta=\frac{P_{O}}{\dot{Q}_{c}}=\frac{\left(T_{H}-T_{C}\right)}{T_{C}} \frac{\left(1+Z T_{M}\right)^{\frac{1}{2}}-1}{\left(1+Z T_{M}\right)^{\frac{1}{2}}+\frac{T_{C}}{T_{H}}}
$$

$Z T_{M}$ represents the figure-of-merit of the device, calculated at temperature $T_{M}$ with eq. 2, $T_{C}$ and $T_{H}$ are the temperatures at the hot and the cold sides, respectively and $T_{M}$ is the mean temperature: $\left(T_{C}+T_{H}\right) / 2$. As stated by eq 3 , a higher efficiency is obtained with a higher value of $Z T$ and with a higher temperature difference between the faces $\left(T_{H}-T_{C}\right)$. However, the application of Eq. 3 is not straightforward, since the properties used in the calculation of $Z T$ change with temperature. Fig. 5 presents the variation of the Seebeck coefficient, the thermal conductance, the electrical resistance and the figure-of-merit (ZT) of a typical thermoelectric module, as function of temperature. The module 9505/127/150B, $15 \mathrm{~A}, 17.5 \mathrm{~V}$, $40 \times 40 \times 3.5 \mathrm{~mm}$ from Ferrotec was used in the graph of fig. 5 and subsequent calculations. A second order polynomial approximation for each parameter is also presented

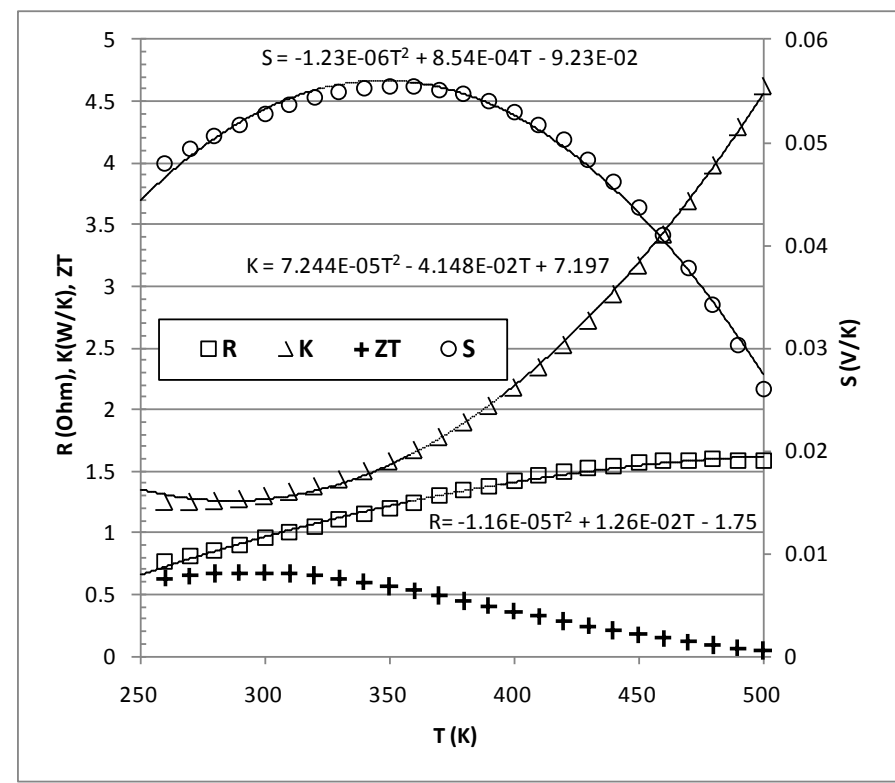

FIGURE 5 - Effect of temperature (T) on thermoelectric properties. A polynomial second order regression was assumed for each thermoelectric parameter, as presented in the graph.

A thermoelectric module was placed between a copper plate heated up to a controlled temperature and a copper plate connected to a heat-sink. The voltage and current for different electrical loads, were measured, with five temperature differences $\left(\Delta T=\{75,47,30,13,8\}{ }^{\circ} \mathrm{C}\right)$. Despite the small temperature difference, these results, plotted on fig. 6, demonstrate the ability to produce electricity from a temperature gradient. Moreover, the almost linear V-I plot, allows the implementation of simple Maximum-Power-PointTracking (MPPT) electronic circuit to use the available power in an efficient manner, charging the vehicle batteries at full available power.
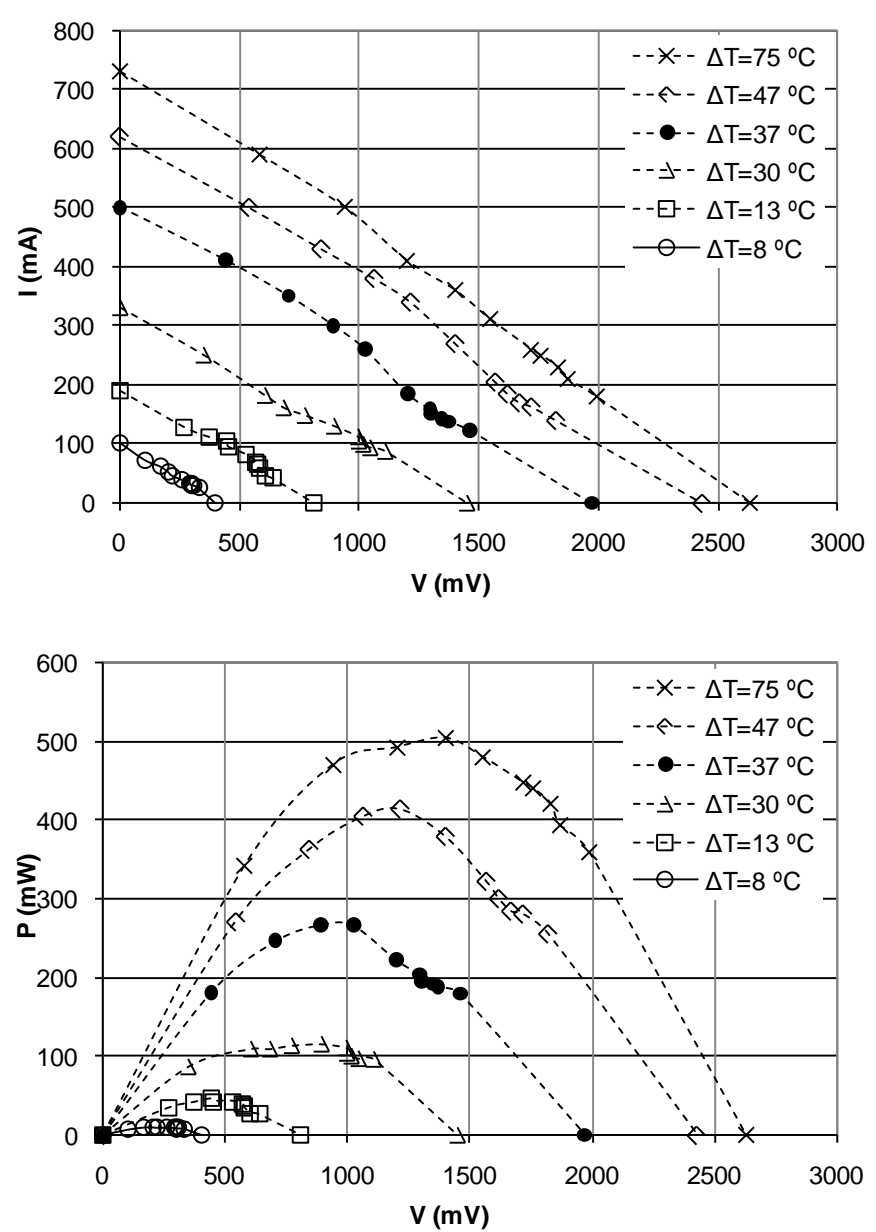

FIGURE 6: Voltage $(V)$ and power $(P)$ output in experimental characterization of thermoelectric modules, for temperature differences between hot and cold face $(\Delta T)$ from $8^{\circ} \mathrm{C}$ to $75^{\circ} \mathrm{C}$.

\section{THERMOELECTRIC GENERATOR MODELLING}

A thermoelectric generator (TEG) for exhaust gases, as the one seen in Fig. 7, is composed of several components. One of them is the heat recovery block, with a centre hole. The hot gases circulate along this hole and transfer heat to the block. Around the block several thermoelectric modules conduct this heat to a water cooled part, on the other side of the thermoelectric modules. The temperature difference between the centre block and the cooled block (between each side of the thermoelectric module) produces a voltage across the module, due to the Seebeck effect. 


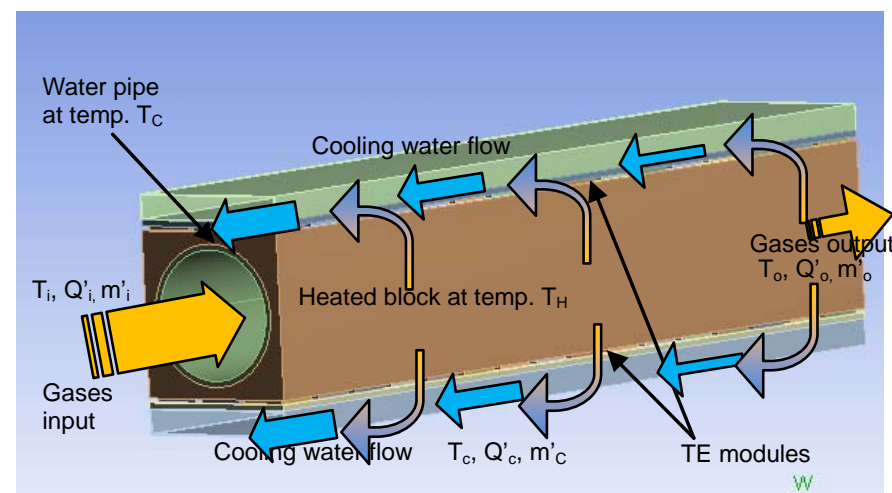

FIGURE 7 - Artwork of a thermoelectric generator for waste heat recovery in exhaust gases of a combustion engine

The hot gases enter at a temperature $T_{i}$ and transfer heat to the block at a mean temperature $\mathrm{T}_{\mathrm{H}}$. Considering the mass flow $(\dot{m})$, the specific heat of the gases $\left(\mathrm{C}_{\mathrm{P}}\right)$, the inner area of the pipe (A), the temperature of the gases output $\left(T_{O}\right)$ and the heat transfer coefficient from the gases to the pipe, $h$, the temperature of the block is calculated with equation 4

$$
T_{O}=T_{H}+\left(T_{i}-T_{H}\right) e^{-\frac{h A}{\dot{m} c_{P}}}
$$

Using copper as the block material and for the conditions of the study, the calculated Biot number is 0.6, implying that an uneven temperature distribution will occur along the body. This renders the use of a global average temperature within the calculations somehow inaccurate, so a more detailed thermal analysis (finite element modelling) was subsequently carried out.

The heat transfer rate $\left(\dot{Q}_{i}\right)$ between the gases within the pipe (at temperature $T_{i}$ ) and the air (at temperature $T_{a m b}$ ) can be related to the mass flow $(\dot{m})$ :

$$
\dot{Q}_{i}=\dot{m} C_{P}\left(T_{i}-T_{a m b}\right)
$$

Considering $\gamma=e^{-\frac{h A}{m c_{p}}}$ eq. 4 can be simplified as:

$$
T_{O}=\gamma T_{i}+(1-\gamma) T_{H}
$$

The heat transfer rate $\left(\dot{Q}_{c}\right)$ to the block can be calculated with eq. 6

$$
\dot{Q}_{c}=h A\left(\Delta T_{M}\right)
$$

$\Delta \mathrm{T}_{\mathrm{M}}$ the logarithmic mean temperature difference of the gases to the pipe, calculated with eq 8 , with an error below $1 \%$ [14]

$$
\Delta T_{M}=\frac{T_{O}-T_{i}}{\ln \frac{T_{H}-T_{O}}{T_{H}-T_{i}}}
$$

The thermoelectric modules transfer the heat from the heated block to the water pipe at the cold side. The temperature at the cold side $\left(T_{C}\right)$ is considered constant, and equal to the temperature at the cold side of the thermoelectric generator. This can be achieved with a large water flow. The hot side of the thermoelectric generator has the same temperature of the heated block $\left(T_{H}\right)$. The heat transfer rate is calculated considering the temperature at the hot and cold sides of the thermoelectric module ( $T_{H}$ and $T_{C}$ respectively), the number of modules $(n)$ and the mean thermal conductance of each module $\left(K_{P}\right)$. The mean value is used because $K_{\mathrm{P}}$ is not constant over the working temperature range.

$$
\dot{Q}_{c}=n \cdot\left(T_{H}-T_{C}\right) \cdot K_{P}
$$

$Q_{c}^{\prime}$ from eq 7 is equal to $\dot{Q}_{c}$ in eq 9. Replacing $\Delta T_{M}$ in eq 7 with $\Delta T_{M}$ from eq 8:

$$
h A\left(\frac{T_{O}-T_{i}}{\ln \frac{T_{H}-T_{O}}{T_{H}-T_{i}}}\right)=n \cdot\left(T_{H}-T_{C}\right) \cdot K_{P}
$$

with $T_{0}=\gamma T_{i}+(1-\gamma) T_{H}$. Solving in order to $T_{H}$ :

$$
T_{H}=\frac{A h(\gamma-1) T_{i}+K_{P} n \ln \gamma T_{C}}{A h(\gamma-1)+K_{P} n \ln \gamma} \text {, with } \gamma=e^{-\frac{h A}{m^{\prime} C_{p}}}
$$

The temperature at the heated block $\left(T_{H}\right)$ has a linear correlation with the temperature of the waste gases entering the pipe $\left(T_{i}\right)$.

The thermoelectric modules produce a voltage $\left(V_{O}\right)$ that is proportional to the temperature difference between the hot and the cold plates of each module (eq. 12). $S$ is the mean Seebeck coefficient (considering the variation of the Seebeck coefficient with temperature) of the thermoelectric module. The mean Seebeck coefficient is considered, since the Seebeck coefficient is not constant over the working temperature range. The thermal resistance of the hot and the cold plates of the thermoelectric module and of the contact between these plates and the heated block and cold block are neglected in this approximation. All modules are considered to be connected electrically in series, thus the total voltage generated $\left(V_{O}\right)$ and the total internal resistance $\left(R_{i}\right)$ are the sum of the voltage produced by each module and the internal resistance of each module, respectively.

$$
V_{O}=n S\left(T_{H}-T_{C}\right)
$$


The maximum power transfer from the modules to the load $\left(P_{O}\right)$ occurs when the load resistance $\left(R_{L}\right)$ equals the mean internal resistance of the modules $\left(R_{i}\right.$ is the electrical resistance of each module and $n \cdot R_{i}$ is the total resistance, when the modules are connected in series). A mean value is used since the resistance is not constant over the working temperature range. The temperature of the hot side $\left(T_{H}\right)$ is calculated with eq 11 , considering the heat recovery system.

$$
P_{O}=\frac{\left(S\left(T_{H}-T_{C}\right)\right)^{2}}{4 R_{i}}
$$

The conversion efficiency $(\eta)$, considering the power of the input gases (heat transfer rate, $Q_{i}^{\prime}$ ) and the electrical power available at output of the module $\left(P_{O}\right)$ is calculated [15] by eq 14:

$$
\eta=\frac{P_{O}}{Q_{i}^{\prime}}=\frac{\left(S\left(T_{H}-T_{C}\right)\right)^{2}}{4 \dot{m} c_{P}\left(T_{i}-T_{a m b}\right) R_{i}}
$$

The values of $\alpha, K_{P}$ and $R_{i}$ depend on temperature, as stated before. For this reason, mean values are used in equation 14, as calculated previously.

A generator was designed for a $60 \mathrm{~kW}$ waste heat power $\left(\dot{Q}_{i}\right)$, with a maximum temperature of gases of $T_{i}=1000 \mathrm{~K}$ and a mass flow $\dot{m}=0.071 \mathrm{~kg} / \mathrm{s}$. The maximum working temperature of current commercial thermoelectric modules is around $500 \mathrm{~K}$. Considering this value, at least 72 modules must be used to ensure this limit is not exceeded. In this design 96 modules were considered, arranged in two arrays of $16 \times 3$, at each side of the generator, allowing a maximum temperature of the heated block of $480 \mathrm{~K}\left(207^{\circ} \mathrm{C}\right)$. This represents a $800 \times 140 \times 140 \mathrm{~mm}$ heated block, with a $120 \mathrm{~mm}$ diameter hole for gases input, with a finned structure to achieve higher heat transfer rate (an internal area - $A$ of this pipe of $0.6 \mathrm{~m}^{2}$ was obtained).

Calculations show a maximum of $39 \mathrm{~kW}$ of power to be transmitted to the water cooling circuit at the cold side of the generator. A mean cold side temperature of $325 \mathrm{~K}$ is maintained. Considering a maximum water temperature increase of $50 \mathrm{~K}$ in the generator, a water mass flow of $0.2 \mathrm{~kg} / \mathrm{s}$ would be necessary at the cooling circuit, with an entry temperature of $300 \mathrm{~K}$ and an output maximum temperature of $350 \mathrm{~K}$. At full power $\left(\dot{Q}_{i}=60 \mathrm{~kW}\right)$, the output temperature of the gases is still $540 \mathrm{~K}$, representing $21 \mathrm{~kW}$ of power transmitted to the output of gases, while the heated block achieves $480 \mathrm{~K}$. Values of $h=300 \mathrm{~W} /\left(\mathrm{K} \cdot \mathrm{m}^{2}\right)$ and $c_{P}=1200 \mathrm{~J} /(\mathrm{kg} . \mathrm{K})$ were considered.

A maximum electrical power of $1530 \mathrm{~W}$ is generated (fig. 8), with an open loop voltage of $820 \mathrm{~V}$, if all modules are connected in series. The overall efficiency of the generator at full power, considering the $1530 \mathrm{~W}$ generated power and the $60 \mathrm{~kW}$ of waste heat power available is $2.6 \%$, while the thermoelectric modules have an efficiency of $3.9 \%$.

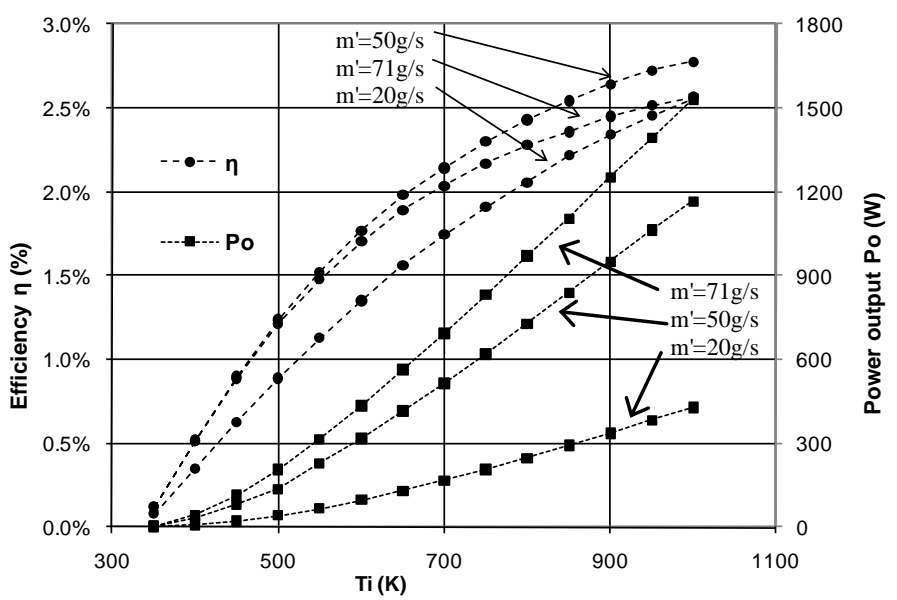

FIGURE 8 - Output power and efficiency of a thermoelectric generator with 96 thermoelectric modules, optimized for a $60 \mathrm{~kW}$ waste heat exhaust system with gases temperature up to $1000 \mathrm{~K}$, for different values of exhaust mass flow ( $\left.\mathrm{m}^{\prime}\right)$ as function of output gases temperature.

Fig. 9 plots the power output and efficiency of the generator, as function of rotation speed and torque of the tested internal combustion engine.
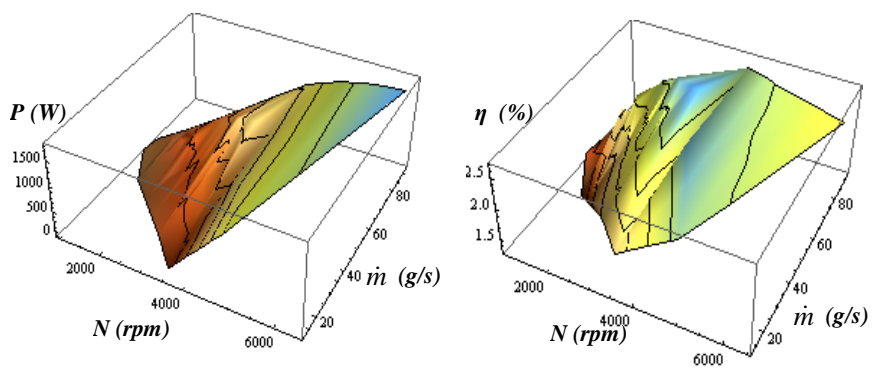

FIGURE 9 - Electric power output (PO) and efficiency ( $\eta$ ) of the thermoelectric generator as function of engine rotation speed (N) and torque (T). Six contour plots are also presented equally distributed from minimum to maximum of scales.

The thermal behaviour of the generator was simulated using finite element modelling (FEM). Fig. 10 represents the temperature calculated by FEM in a copper block with the dimensions presented. Despite the high conductivity of copper, a longitudinal decrease of the block temperature (from $170{ }^{\circ} \mathrm{C}$ to $240{ }^{\circ} \mathrm{C}$ ) is expected along its length, as the inner fluid loses heat. 


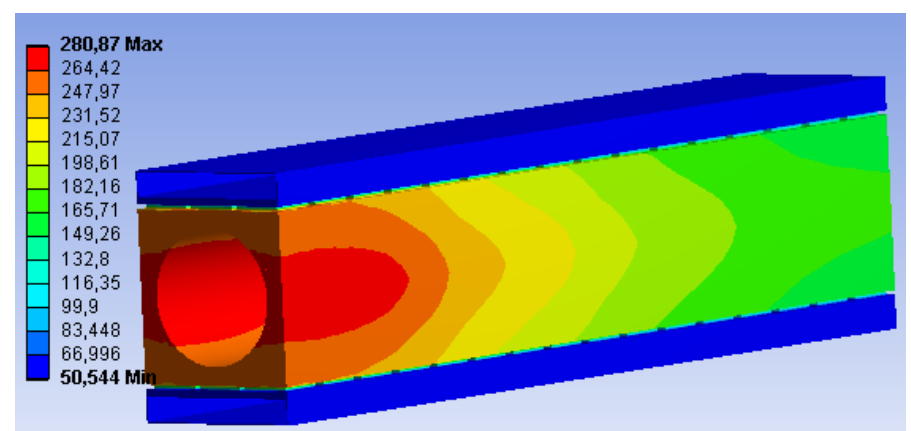

FIGURE 10 - Temperature $\left({ }^{\circ} \mathrm{C}\right)$ profile of a thermoelectric generator in a engine of $60 \mathrm{~kW}$ exhaust gases power ( $T_{i}=1000 \mathrm{~K}$ and $\dot{m}=71 \mathrm{~g} / \mathrm{s}$ ).

\section{IMPROVED THERMOELECTRIC CONVERTER}

Despite the mean temperature of the generator being bellow the maximum working limit (around $220^{\circ} \mathrm{C}$ for best commercial TE modules), the non uniformity of temperature in the heated block of the generator is still a major limitation. Efficiency is reduced in colder areas $\left(T_{H}=170{ }^{\circ} \mathrm{C}\right)$ and the maximum working temperature is exceeded in warmer areas $\left(T_{H}=240^{\circ} \mathrm{C}\right)$. Due to the maximum allowable working temperature of thermoelectric modules, the presented generator must be carefully dimensioned not to overcome this limit. Designing thermoelectric generators for high power engines requires a large number of thermoelectric modules, increasing the size and weight of the generator to impracticable dimensions. Moreover, despite the fact that engines typically run below their maximum power, a large generator (with much higher costs) would have to be designed. If a small generator is pretended, then the temperature on the modules must be limited. On the other hand, since the efficiency of thermoelectric modules increases with higher temperature differentials, it is desirable to maintain these modules working near their temperature limit. This could be obtained if the number of active thermoelectric modules of the generator $(n)$ could increase as the input power increases.

The use of heat pipes (HP) is the most effective solution to control temperature [16], since no movable parts are required, thus decreasing maintenance and increasing lifetime. Fig 11 shows an artwork describing the principle used in this solution:

\section{Heat Transfer Calculations}

When the temperature of the block increases, heat is transferred through the heat-pipe to the thermoelectric modules situated on the top (condensing side) of the HP. It was assumed that each module would be capable of receiving $450 \mathrm{~W}$ of heat (at approximately $200{ }^{\circ} \mathrm{C}$ ). Initial tests and commercial data show that we could expect about $350 \mathrm{~W}$ for a $\mathrm{HP}$ of $25 \mathrm{~cm}$ diameter. The design solution of fig. 11 was based on these assumptions, and we decided to set four HP together (1400 W) supplying heat to groups of 3 modules each $(1350 \mathrm{~W})$. The referred figure shows 10 of the described assemblies, in a total of $40 \mathrm{HP}$ and 30 modules.

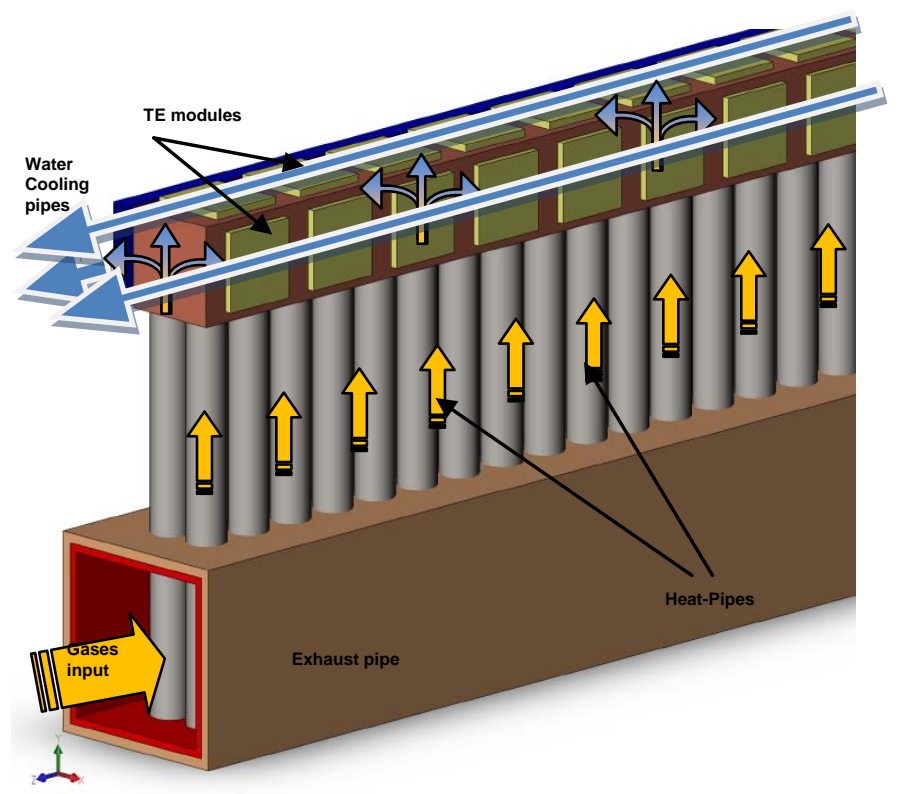

\section{FIGURE 11 - Artwork of a thermoelectric generator for waste heat recovery in exhaust gases of combustion engines, using heat pipes.}

The lower part of each HP (vaporization side) should protrude the exhaust pipe of the engine. Assuming a square exhaust pipe with $100 \mathrm{~mm}$ of side, that cross flow area would be crossed by two HP, therefore creating a 20 array of two HP side by side (see fig. 11).

The heat transfer condition between the exhaust gases will be the limiting factor for heat transfer, so an analysis is herein performed.

Assuming a transversal cylinder exposed to the exhaust gases, the following equation can be used:

$$
\overline{\mathrm{Nu}_{\mathrm{D}}}=\frac{\overline{\mathrm{h} D}}{\mathrm{k}}=0.3+\frac{0.62 \operatorname{Re}_{\mathrm{D}}^{1 / 2} \operatorname{Pr}^{1 / 3}}{\left[1+(0.4 / \mathrm{Pr})^{2 / 3}\right]^{1 / 4}}\left[1+\left(\frac{\mathrm{Re}_{\mathrm{D}}}{282000}\right)^{5 / 8}\right]^{4 / 5}
$$

where $\operatorname{Re}_{\mathrm{D}}=\frac{\rho v \mathrm{D}}{\mu}=\frac{\mathrm{vD}}{v}$ is the Reynolds number, based on the HP diameter and the exhaust flow conditions (velocity and temperature);

$N u_{D}$ is the Nusselt Number

$\mathrm{h}$ is the heat transfer coefficient (gas-HP);

$\mathrm{D}$ is the HP diameter;

$\mathrm{k}$ is the thermal conductivity;

Pr is the Prandtl number;

$\rho$ is the gas density;

$\mathrm{v}$ is the gas velocity;

$\mu$ is the gas viscosity. 
The various properties $(k, \rho, \mu, P r)$ are taken at film temperature.

As the flow at the exhaust is highly pulsating, the heat transfer coefficient $h$ will be enhanced by a factor of 2 . For the conditions of full power ( $86 \mathrm{~g} / \mathrm{s}$ of exhaust gases at $780{ }^{\circ} \mathrm{C}$ ) the retrieved thermal power from the HP is more than $700 \mathrm{~W}$, much more than the $350 \mathrm{~W}$ required. For these conditions the total thermal power present at the exhaust is more that 3 times the total power required for the $40 \mathrm{HP}$. For light load (40\% throttle at $3000 \mathrm{rpm})$ the exhaust conditions $\left(25 \mathrm{~g} / \mathrm{s}, 650^{\circ} \mathrm{C}\right)$ enable to retrieve $10 \mathrm{~kW}$ from the exhaust enthalpy. This is almost the full capacity required by the 30 modules $(13.5 \mathrm{~kW})$. For these conditions the exhaust temperature after all the HP is $290{ }^{\circ} \mathrm{C}$.

The previously described equations (eq.1 to 14) apply to each block in this improved generator. However, the temperature of each block is limited to $490 \mathrm{~K}$. The graph in fig. 12 plots the electrical output power and efficiency of a generator with 30 thermoelectric modules used in the described engine.

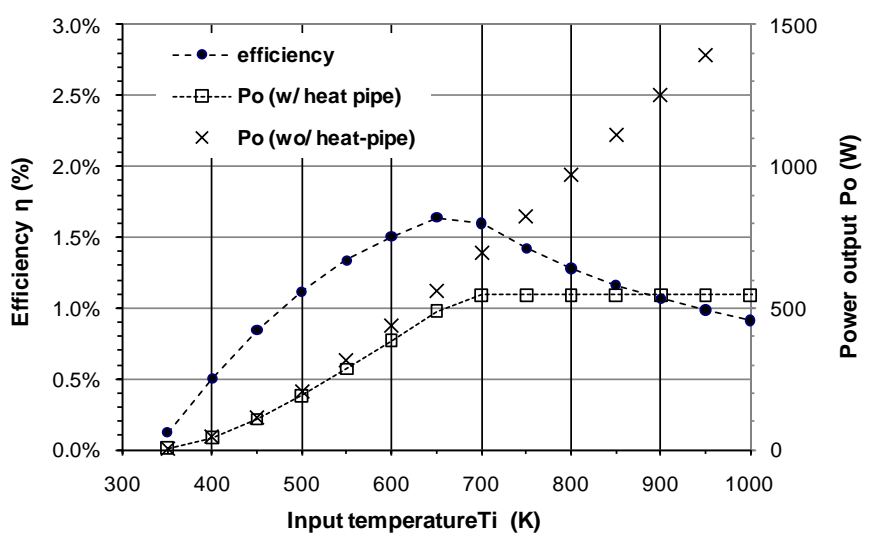

FIGURE 12 - Output power and efficiency of heat pipe controlled thermoelectric generator as a function of output exhaust gases temperature.

A maximum electrical power output of $550 \mathrm{~W}$ is expected, for an input power $\left(\dot{Q}_{i}\right)$ above $30 \mathrm{~kW}$. The maximum estimated efficiency is $1.7 \%$.

Each thermoelectric module can divert a maximum power of $450 \mathrm{~W}$, considering the maximum working temperature of $490 \mathrm{~K}\left(217^{\circ} \mathrm{C}\right)$ and a cold side temperature of $325 \mathrm{~K}\left(52{ }^{\circ} \mathrm{C}\right)$. The maximum heat transfer demand in each heat-pipe is $337 \mathrm{~W}$, considering 30 thermoelectric modules and 40 heat pipes. This can be achieved with a heat pipe diameter of $25 \mathrm{~mm}$.

\section{Variable Conductance Heat Pipes}

While a basic heat pipe (HP) contains a single fluid in its interior (the phase-changing working fluid), a variable conductance heat pipe (VCHP) additionally contains a low density, non-condensable gas in its interior (see fig. 13) located at its top, generally within a reservoir or expansion tank.
Independently of the type of HP, the higher the heat source temperature, more liquid will vaporize at the evaporator and more heat will be transferred to the heat sink by condensation. In the case of simple HP's the increase of the heat source temperature is accompanied by a strong increase of the internal pressure. This is not so in the case of VCHP's, because the large mass of gas at the reservoir is able to reduce its volume and thus mitigate the pressure increase.

Now, the inner temperature of a HP is intimately linked with the boiling temperature of the liquid. Taking into account that the boiling temperature of a liquid increases with pressure, it can be concluded that a limitation of the inner pressure due to the use of a VCHP will yield a limitation of the corresponding working temperature.

This characteristic of VCHP's is very useful for the application under study, because it should be possible to design the VCHP's so that their working temperature will never exceed the maximum allowable temperature of the thermoelectric modules, even under excess thermal loads.

However, care should be taken so that the VHCP will not contain excess gas. If this was to happen, under low working temperatures the gas would not be restrained to the reservoir only and therefore it could block, or at least hamper the access of the vapour to the condensing region, limiting heat transfer at low loads. While this could be useful in particular applications, it is undesirable in the present case and therefore should be avoided $[17,18]$.

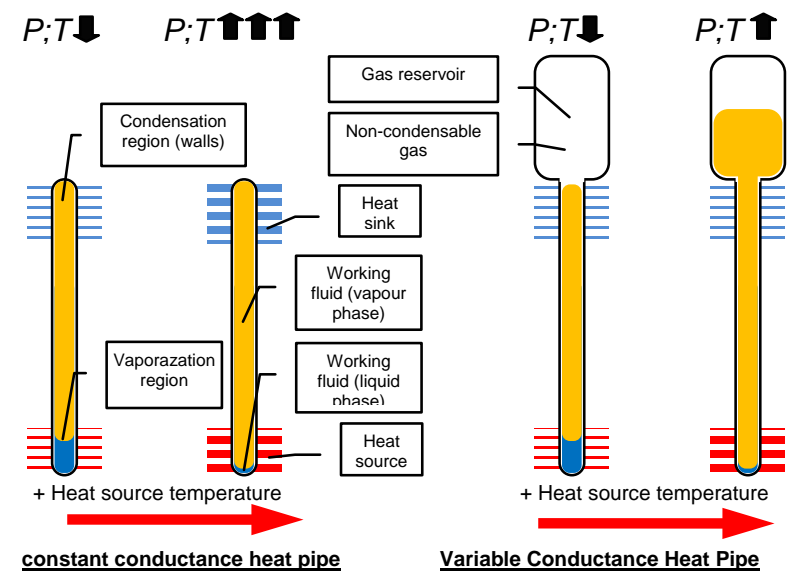

FIGURE 13 - Constant vs. Variable Conductance Heat Pipes

Considering the working temperature of the system, the typical copper-water heat-pipe is not suitable for this application, even considering the use of VCHP's, since during operation its absolute pressure would reach 40 bar. For this application, a suitable working fluid must be used, considering the maximum temperature reaching $250{ }^{\circ} \mathrm{C}$. Diphenyl and diphenyl ether, equivalent to DOWTHERM A, with melting point of $285 \mathrm{~K}$ and boiling point of $540 \mathrm{~K}$, was previously used in intermediate temperature heat-pipes $[16,17]$, and can also be chosen for this application. Also, the HP pipe material cannot be copper, as the exhaust temperatures may be too high for it. Therefore, we 
assumed the necessity of adopting a stronger material, possibly stainless steel. The use of a stronger material may allow the use of water as the working fluid, as the steel would allow the required high water pressures (up to 25 bar, the saturated pressure for $225^{\circ} \mathrm{C}$ ).

\section{CONCLUSIONS}

A system for the recovery of engine exhaust energy by converting it into electricity was presented, using commercially available thermoelectric modules. Considering the output temperature and mass flow of the exhaust gases, a large number of thermoelectric modules would be necessary to support the full power of the engine without damaging these modules. This solution would require a large size and cost for a condition (full power) that is seldom used. To overcome this limitation, a generator using heat pipes to control the temperature in the modules has been suggested. It consists on the use of heat pipes for transferring the heat from the exhaust gases to the thermoelectric generators. If carefully designed, such system is able to ensure a good heat transfer rate while avoiding the overheating of these modules.

Although some initial experimental tests were already done with both the modules and with the heat pipes, this work focuses mainly on the modelling results obtained with the referred thermal design.

It is possible to use heat pipes for the recovery of exhaust heat and the design of the system allows the recovery of a significant part of the exhaust gas enthalpy when the engine is at medium load/speed conditions, but only about one third is attained at full power. However, more modules and heat pipes could be added in order to enhance the recovery under full loads, but these would not be used at the more current conditions, where partial load and speeds prevail.

\section{ACKNOWLEDGMENTS}

This research project was supported by POCI/ENR/59168/2004 and MIT-Pt/EDAM-SMS/0030/2008. F. Brito acknowledges FCT and MIT Portugal programme for post-doctoral grant. SFRH/BPD/51048/2010.

\section{REFERENCES}

[1] L.A.S.B. Martins, J.M.O. Brito, A.M.D. Rocha and J.J.G. Martins, 2009, "Regenerative Braking Potential and Energy Simulations for a Plug-In Hybrid Electric Vehicle Under Real Driving Conditions”, Proceedings of ASME IMECE09, November 13-19, , Lake Buena Vista, Florida, USA.
[2] Jorge J.G. Martins, Krisztina Uzuneanu, Bernardo Ribeiro and Ondrej Jasansky, 2004, "Thermodynamic Analysis of an Over-Expanded Engine", SAE Technical Paper Series, n 200401-0617, included in 'Modeling of Spark Ignition Engines', edited by SAE (ISBN Number: 0-7680-1366-6),

[3] J. LaGrandeur, D. Crane, S. Hung, B. Mazar and A. Eder, 2006, "Automotive waste heat conversion to electric power using skutterudite, TAGS, PbTe and BiTe”, International conference on thermoelectric, p. 343-48.

[4] L. Bell, 2008, “Cooling, heating, generating power, and recovering waste heat with thermoelectric systems", Science, 321, pp. 1457-1461.

[5] J. Heywood, 1988, “Internal Combustion Engines Fundamentals”, McGraw-Hill.

[6] Jorge Martins, 2006, “Motores de Combustão Interna”, 2nd edition, Publindustria, Portugal.

[7] K. Matsubara, 2002, "Development of a high efficient thermoelectric stack for a waste exhaust heat recovery of vehicles”, International conference on thermoelectric, p. 41823.

[8] B. Ribeiro and J. Martins, 2007, "Direct Comparison of an Engine Working under Otto, Miller and Diesel cycles:

Thermodynamic Analysis and Real Engine Performance”, SAE 2007-01-0261.

[9] B. Ribeiro, J. Martins and N. Kothari, "Otto and VCR Miller Engine Performance during the European Driving Cycle”, SAE 2006-01-0440, 2006.

[10] D.M. Rowe, Gao Min, 1998, “Evaluation of thermoelectric modules for power generation”, Journal of Power Sources 73, 193-198.

[11] Jarrod L. Short, Jonathan D’Angelo, Adam D. Downey, Michael A. Pajor, Ed Timm, Harold Schock, Mercouri G. Kanatzidis, Timothy P. Hogan, 2006, "Characterization of Thermoelectric Power Generation Modules Made from New Materials”, Mater. Res. Soc. Symp. Proc. Vol. 886, Materials Research Society.

[12] Timothy P. Hogan et al, 2007, “Nanostructured Thermoelectric Materials and High-Efficiency PowerGeneration Modules”, Journal of Electronic Materials, Vol. 36, No. 7

[13] Gao Min and D.M. Rowe, 2007, “Conversion Efficiency of Thermoelectric Combustion Systems”, IEEE Transactions on Energy Conversion, Vol. 22, No. 2, June. 
[14] Yunus A. Çengel, 1998, "Heat Transfer - A practical approach”, McGraw-Hill, p. 364.

[15] H. J. Goldsmid, 1987, "CRC Handbook of Thermoelectrics", London CRC Press, edited by D.M. Rowe.

[16] Kenji Watanabe, Atsushi Kimura, Kenya Kawabata, Tomoki Yanagida and Mamoru Yamauchi, 2001, "Development of a Variable-Conductance Heat-Pipe for a Sodium-Sulfur (NAS) Battery”, Furukawa Review, No. 20.

[17] W.G. Anderson, 2007, "Intermediate Temperature Fluids for Heat Pipes and LHPs", Proceedings of the 2007 IECEC, AIAA, St. Louis, MO, June 25-27.

[18] A. Devarakonda and W.G. Anderson, 2005, "ThermoPhysical Properties of Intermediate Temperature Heat Pipe Fluids," STAIF 2005, Albuquerque, NM, February 13-17. NASA Report NASA/CR-2005-213582, available from the NASA Glenn Technical Reports Server, http://gltrs.grc.nasa.gov/. 